\title{
Rheumatoid neutrophilic dermatitis
}

\author{
Gabriela Żuk ${ }^{1}$, Kamila Jaworecka ${ }^{1}$, Dominik Samotij ${ }^{1}$, Elżbieta Ostańska ${ }^{2}$, Adam Reich $^{1}$ \\ ${ }^{1}$ Department of Dermatology, University of Rzeszow, Poland \\ ${ }^{2}$ Department of Pathology, University of Rzeszow, Poland
}

\begin{abstract}
Rheumatoid neutrophilic dermatitis is a rare extra-articular manifestation of rheumatoid arthritis, both seropositive and seronegative for rheumatoid factor. The condition most often presents as symmetric erythematous papules, nodules, plaques, and urticaria-like lesions in patients with severe, long-lasting rheumatoid arthritis. We report a case of a 65 -year-old man with well-controlled rheumatoid arthritis, who developed rheumatoid neutrophilic dermatitis on the right lower leg. The biopsy of skin lesions revealed an intense, neutrophilic dermal infiltrate, microabscesses, and leukocytoclasis without vasculitis. The patient responded well to pulses of intravenous methylprednisolone. We present this patient due to the rarity of the disease and atypical unilateral manifestation involving the flexural surfaces of the lower leg.
\end{abstract}

Key words: rheumatoid arthritis, rheumatoid neutrophilic dermatitis, dermatological manifestations, neutrophilic dermatoses.

\section{Introduction}

Rheumatoid arthritis (RA) is a chronic synovial inflammatory disease, characterized by symmetric and destructive polyarthritis. Extra-articular manifestations of RA are also well known, including disorders of the cardiovascular, respiratory, nervous, and urinary systems, eyes and skin. Regarding the skin, rheumatoid nodules are the most frequent cutaneous abnormalities [1].

Patients with RA may also manifest a wide spectrum of other skin conditions, and dermatological involvement tends to occur in patients with more severe or active RA. However, in some patients, RA-related dermatoses may occur although the joint symptoms are well controlled.

Here, we present a case of rheumatoid neutrophilic dermatitis (RND), a rare neutrophilic skin condition, in a patient with RA being treated with methotrexate.

\section{Case report}

A 65-year-old man with a 10-year history of rheumatoid arthritis (RA) was admitted to the Department of Dermatology due to numerous nodules and papules located on the right lower leg that were resistant to the treatment with topical steroids and topical and systemic antibiotics.

According to the medical history, the first lesions appeared after a minor injury resulting from a bike accident two months earlier. The patient was treated for RA with methotrexate in a dose of $25 \mathrm{mg} /$ week and $2 \mathrm{mg} /$ day of methylprednisolone. At the first admission to the hospital, RA symptoms were well controlled with the above-mentioned treatment. In addition, the patient suffered from arterial hypertension and hypercholesterolemia for which he received $2.5 \mathrm{mg} /$ day of bisoprolol with $1.5 \mathrm{mg} /$ day of indapamide and $20 \mathrm{mg} /$ day of atorvastatin, respectively.

On admission, grouped bluish-purple nodules and papules were present on the flexor area of the right shin (Fig. 1). The patient did not report any subjective complaints such as itching or burning sensations within the skin lesions. The laboratory examination confirmed the presence of rheumatoid factor in the serum as well as eosinophilia (8.6\%, normal range $2-4 \%$ ) and elevated levels of C-reactive protein (CRP) $(3.5 \mathrm{mg} / \mathrm{dl}$, normal range $<1 \mathrm{mg} / \mathrm{dl})$, lactate dehydrogenase $(\mathrm{LDH})(330 \mathrm{U} / \mathrm{l}$, 


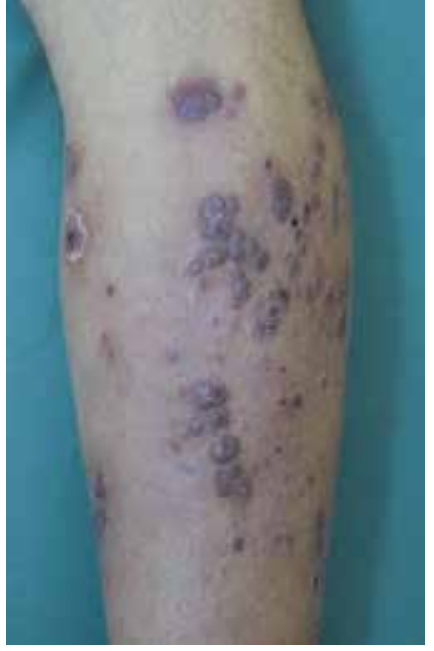

Fig. 1. Grouped bluish-purple nodules and papules on the flexor area of the right shin.

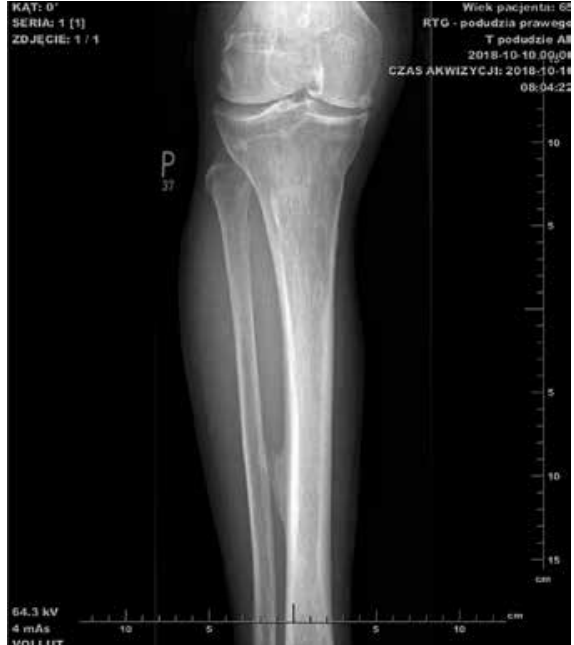

Fig. 2. Osteochondral outgrowth in the medial part of the tibia on a computed tomography scan.
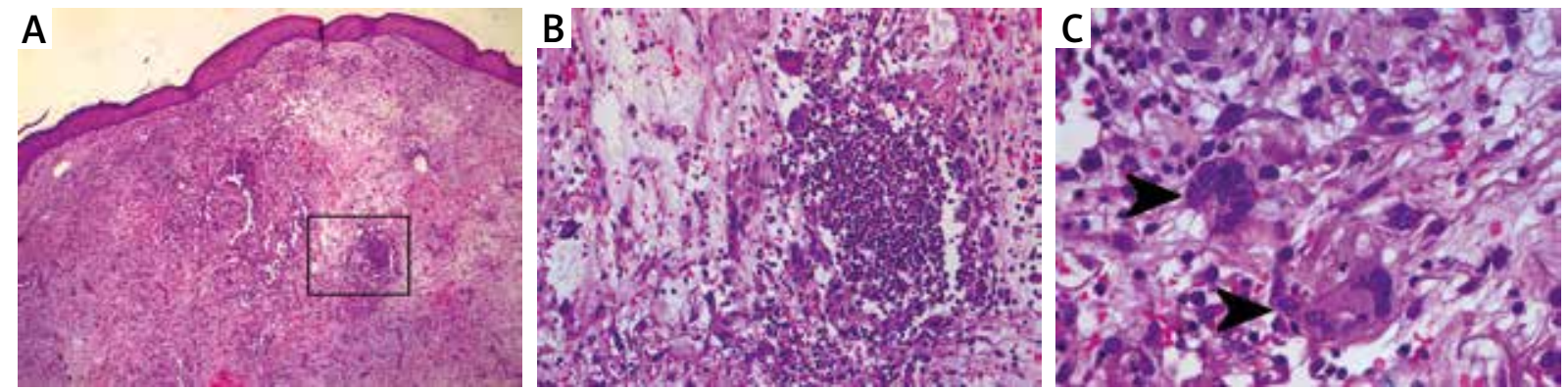

Fig. 3. A dense neutrophilic infiltrate with histiocytes, multinucleated giant cells and neutrophils locally forming microabscesses (hematoxylin and eosin, original magnification $\times 4$ ) (A). Enlarged area marked on previous image - microabscess with leukocytoclasis within the vessel wall (hematoxylin and eosin, original magnification $\times 20)(B)$. Multinucleated giant cells within the inflammatory infiltrate (arrowheads) (hematoxylin and eosin, original magnification $\times 40)(C)$.

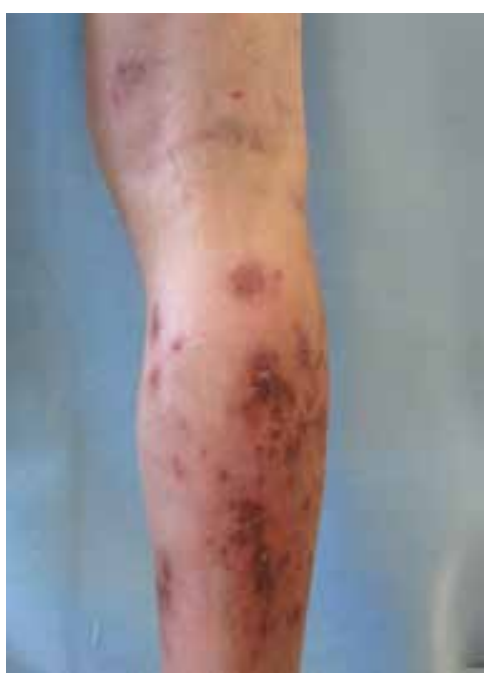

Fig. 4. The lesions from Fig. 1 after 7 intravenous pulses of methylprednisolone - mostly postinflammatory hyperpigmentation with only a few active lesions is seen. normal range $120-246 \mathrm{U} / \mathrm{l})$ and $\beta 2$-microglobulin (5.03 mg/l, normal range 0.81-2.19 mg/l).

Sonography revealed reactively enlarged axillary and inguinal lymph nodes with a maximum dimension of $20 \mathrm{~mm}$. X-ray examination of the right lower leg demonstrated an osteochondral outgrowth in the medial part of the tibia which was also visualized with a computed tomography (CT) scan (Fig. 2).

Bacteriological and fungal examinations of the smear from the lesions as well as a biopsied skin sample were negative. Histological assessment of the skin biopsy revealed edema of the papillary and reticular dermis, proliferation of small vessels, and a dense neutrophilic infiltrate with histiocytes, a few multinucleated giant cells and neutrophils forming microabscesses locally (Fig. 3).

The patient was started on methylprednisolone pulse therapy ( $3 \times 500 \mathrm{mg}$ i.v. given every month) combined with dapsone $100 \mathrm{mg} /$ day and topical betamethasone ointment. The other drugs were taken at the same doses as before. One month later dapsone was stopped 
due to megaloblastic anemia, mild thrombocytopenia and hyperbilirubinemia and the dose of methotrexate was reduced to $15 \mathrm{mg} /$ week. After another month the abnormal laboratory parameters normalized; however, the patient complained about the significant deterioration of joint symptoms related to RA, so the dose of methotrexate was increased gradually to $25 \mathrm{mg} /$ week, which resulted in decrease of RA activity. In the meantime, methylprednisolone pulse therapy resulted in significant improvement of existing skin lesions (Fig. 4). The patient continues the treatment with reduced doses of steroids, being under regular follow-up.

\section{Discussion}

Skin problems in patients with RA may be divided into RA-specific conditions, RA-related dermatoses and skin problems due to the treatment taken by a patient.

Rheumatoid arthritis-specific skin lesions are seen only in RA patients and include rheumatoid nodules, rheumatoid nodulosis, accelerated rheumatoid nodulosis, rheumatoid vasculitis and RND.

Rheumatoid arthritis-related skin diseases include dermatoses that are linked with RA but may also occur in connection with other conditions. This group of skin diseases includes Sweet's syndrome, pyoderma gangrenosum, neutrophilic palisading granulomatous vasculitis, Raynaud's phenomenon, livedo racemosa interstitial granulomatous dermatitis with arthritis (IGDA), and erythema elevatum diutinum (EED) [2].

Rheumatoid neutrophilic dermatitis is a rare entity, first described in 1978 by Ackerman, which belongs to the group of neutrophilic dermatitis [3]. The disease affects women more often, with a 1:2 male to female ratio [4]. It is a specific skin manifestation of RA with a prevalence of $0.9-1.8 \%$ among all RA patients $[5,6]$. The pathogenesis in unknown, but it is suggested to be an immune-complex-mediated disease [1].

Rheumatoid neutrophilic dermatitis occurs more commonly in patients who have severe, long-lasting seropositive arthritis and clinically manifests as asymptomatic erythematous papules, nodules, plaques or urticaria-like lesions [5-7]. Vesicles, blisters, ulcers and annular lesions are less frequent $[4,8]$. Skin lesions are usually symmetric, but sometimes, like in our case, may be distributed asymmetrically [8-10]. Extensor surfaces of extremities and joints are favored locations with a predilection to the dorsal surfaces of hands and arms [11-13]. In that sense our patient is quite unique, as eruptions were located on the lower leg, involving predominantly the flexural aspect of the shin.

The differential diagnosis of RND in our patient included sporotrichosis, cutaneous lymphoma and reac- tion to a foreign body (because of injury reported by the patient) $[10,11,13]$. The final diagnosis was made based on the microscopic examination showing typical histologic features of RND: primarily dense dermal infiltration consisting predominantly of neutrophils, papillary dermal microabscesses, and leukocytoclasis without vasculitis $[9,14]$. Spongiosis, intraepidermal and subepidermal vesiculation, subepidermal edema and basophilic degeneration of the dermal collagen may also be seen on some occasions $[9,15,16]$.

\section{Conclusions}

Rheumatoid neutrophilic dermatitis may be treated with topical or systemic corticosteroids or dapsone (50-100 mg/day) [7, 17, 18]. Antimalarials, such as hydroxychloroquine, have also been shown to be effective [19]. Sometimes, cyclophosphamide was the only drug that provided improvement [20]. On the other hand, some lesions disappear spontaneously. Skin lesions heal without scarring, though sometimes leaving skin discolorations, as in our patient [10].

Adam Reich has worked as a consultant or speaker for pharmaceutical companies and participated as a principal investigator or subinvestigator in clinical trials sponsored by pharmaceutical companies.

The other authors declare no conflict of interest.

\section{References}

1. Tilstra JS, Lienesch DW. Rheumatoid Nodules. Dermatol Clin 2015; 33: 361-371.

2. Cugno M, Gualtierotti R, Meroni PL, Marzano AV. Inflammatory Joint Disorders and Neutrophilic Dermatoses: a Comprehensive Review. Clin Rev Allergy Immunol 2018; 54: 269-281.

3. Alavi A, Sajic D, Cerci FB, et al. Neutrophilic dermatoses: an update. Am J Clin Dermatol 2014; 15: 413-423.

4. Fujio Y, Funakoshi T, Nakayama K, et al. Rheumatoid neutrophilic dermatosis with tense blister formation: a case report and review of the literature. Australas J Dermatol 2014; 55: e12-14.

5. Xue Y, Cohen JM, Wright NA, Merola JF. Skin Signs of Rheumatoid Arthritis and its Therapy-Induced Cutaneous Side Effects. Am J Clin Dermatol 2016; 17: 147-162.

6. Ziemer M, Müller AK, Hein G, et al. Incidence and classification of cutaneous manifestations in rheumatoid arthritis. J Dtsch Dermatol Ges 2016; 14: 1237-1246.

7. Hata T, Kavanaugh A. Rheumatoid arthritis in dermatology. Clin Dermatol 2006; 24: 430-437.

8. Filosa A, Filosa G. Neutrophilic dermatoses: a broad spectrum of disease. G Ital Dermatol Venereol 2018; 153: 265-272.

9. Brown TS, Fearneyhough PK, Burruss JB, Callen JP. Rheumatoid neutrophilic dermatitis in a woman with seronegative rheumatoid arthritis. J Am Acad Dermatol 2001; 45: 596-600. 
10. Chua-Aguilera CJ, Möller B, Yawalkar N. Skin Manifestations of Rheumatoid Arthritis, Juvenile Idiopathic Arthritis, and Spondyloarthritides. Clin Rev Allergy Immunol 2017; 53: 371-393.

11. Defaria D, Kroumpouzos G. Rheumatoid neutrophilic dermatitis as presenting sign of seronegative arthritis. Acta Derm Venereol 2004; 84: 236-237.

12. Ashchyan HJ, Nelson CA, Stephen S, et al. Neutrophilic dermatoses: Pyoderma gangrenosum and other bowel- and arthritisassociated neutrophilic dermatoses. J Am Acad Dermatol 2018; 79: 1009-1022.

13. Caucanas M, Heylen A, Rolland F, et al. Associated pyoderma gangrenosum, erythema elevatum diutinum, and Sweet's syndrome: the concept of neutrophilic disease. Int J Dermatol 2013; 52: 1185-1188.

14. Lora V, Cerroni L, Cota C. Skin manifestations of rheumatoid arthritis. G Ital Dermatol Venereol 2018; 153: 243-255.

15. Lu Cl, Yang CH, Hong HS. A bullous neutrophilic dermatosis in a patient with severe rheumatoid arthritis and monoclonal IgA gammopathy. J Am Acad Dermatol 2004; 51 (Suppl 2): 94-96.
16. MacAya A, Servitije O, Jucglà A, Peyri J. Rheumatoid neutrophilic dermatitis associated with pyoderma gangrenosum. Br J Dermatol 2000; 142: 1246-1248.

17. Lazarov A, Mor A, Cordoba M, Mekori YA. Rheumatoid neutrophilic dermatitis: an initial dermatological manifestation of seronegative rheumatoid arthritis. J Eur Acad Dermatol Venereol 2002; 16: 74-76.

18. Schadt CR, Callen JP. Management of neutrophilic dermatoses. Dermatol Ther 2012; 25: 158-172.

19. Gerbing EK, Metze D, Luger TA, Ständer S. Interstitial granulomatous dermatitis without arthritis: successful therapy with hydroxychloroquine. J Dtsch Dermatol Ges 2003; 1: 137-141.

20. Mashek HA, Pham CT, Helm TN, Klaus M. Rheumatoid neutrophilic dermatitis. Arch Dermatol 1997; 133: 757-760. 